\title{
Case Report: Using basic liver function tests as a guide to
}

\section{suspected Wilson's disease [version 1; peer review: 1}

\section{approved, 1 approved with reservations]}

\author{
Sudeep Adhikari (D1, Prashant Kumar Shah (D2, Yuba Raj Sharma² \\ ${ }^{1}$ Department of Internal Medicine, Pyuthan Hospital, Pyuthan, 22300, Nepal \\ ${ }^{2}$ Department of Internal Medicine, Patan Academy of Health Sciences, Kathmandu, 26500, Nepal
}

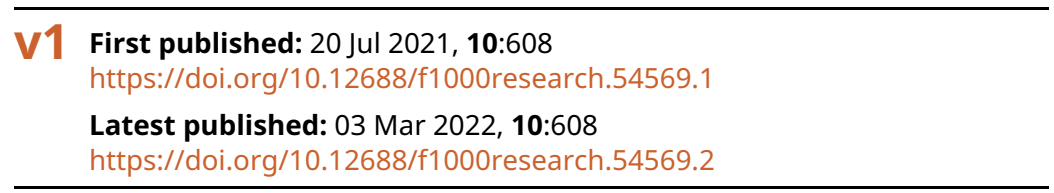

\section{Abstract}

We present a case of a 36-year-old female patient who presented with subacute liver disease with a history of alcohol abuse. On basic liver function tests (LFT), she had aspartate transaminase / alanine transaminase $>2.2$ and alkaline phosphatase / total bilirubin $<4$. This pattern in acute liver failure patients signifies Wilson's disease. Its presence in our patient with subacute liver disease also prompted us to suspect Wilson's disease and we extended the liver disease screen to include slit lamp eye examination for Kayser-Fleischer rings, serum ceruloplasmin and 24-hour urinary copper level, which led to the diagnosis. She improved clinically and biochemically with zinc acetate therapy. As screening for rare diseases is not always possible in lowincome countries, this case demonstrates the usefulness of the basic LFT as a guide for suspecting Wilson's disease in patients with liver disease.

Keywords

Wilson's disease, liver disease, basic liver function tests, Nepal

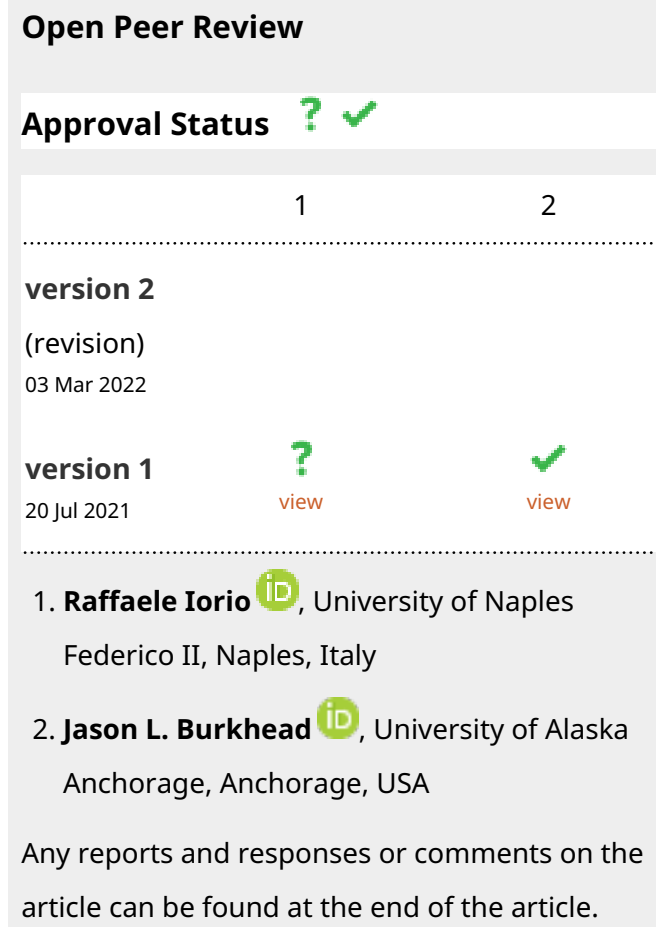

\footnotetext{
Corresponding author: Sudeep Adhikari (sudeepadh123@gmail.com)
}

Author roles: Adhikari S: Conceptualization, Writing - Review \& Editing; Shah PK: Conceptualization, Writing - Original Draft Preparation; Sharma YR: Supervision, Writing - Review \& Editing

Competing interests: No competing interests were disclosed.

Grant information: The author(s) declared that no grants were involved in supporting this work.

Copyright: $\odot 2021$ Adhikari $S$ et al. This is an open access article distributed under the terms of the Creative Commons Attribution License, which permits unrestricted use, distribution, and reproduction in any medium, provided the original work is properly cited.

How to cite this article: Adhikari S, Shah PK and Sharma YR. Case Report: Using basic liver function tests as a guide to suspected Wilson's disease [version 1; peer review: 1 approved, 1 approved with reservations] F1000Research 2021, 10:608 https://doi.org/10.12688/f1000research.54569.1

First published: 20 Jul 2021, 10:608 https://doi.org/10.12688/f1000research.54569.1 


\section{Introduction}

Wilson's disease is an autosomal recessive disorder of copper metabolism that leads to liver disease and neuropsychiatric manifestations. The majority of patients are diagnosed between the ages of five and 35 years. This disease is usually suspected in patients with liver disease of uncertain etiology, especially if accompanied by neuropsychiatric symptoms. But it can also present with liver abnormalities alone. Untreated, this disease is universally fatal, with patients dying from cirrhosis or progressive neurologic disease. ${ }^{1}$ Hence its timely recognition is important. It is not usually diagnosed in resource-limited countries as diagnostic tests are not easily available. Here we present a case of Wilson's disease from Nepal. The patient presented with liver disease (without neuropsychiatric features), and we discuss how basic liver function test parameters can be used as a guide to suspected Wilson's disease.

\section{Case}

A 36-year-old woman from Lalitpur, Nepal presented to the emergency department of Patan Hospital in December 2018, with complaints of abdominal distension and yellowish discoloration of the skin for two months and shortness of breath for the last 10 days. She had no history of fever, cough, abdominal pain, nausea, vomiting, black stools, altered sensorium or abnormal body movement. She had a history of consuming home-made alcohol, almost daily for 12 years, although quantification of the intake could not be done.

On examination she appeared icteric and pale. Blood pressure was $90 / 60 \mathrm{~mm} \mathrm{Hg}$, pulse 78 beats per minute, respiratory rate 20 breaths per minute, temperature 98.7 Fahrenheit and oxygen saturation of $97 \%$ at room temperature. Abdomen was distended and non-tender, liver and spleen were not palpable and shifting dullness was present. Chest examination showed decreased air entry. Bilateral pitting pedal edema was noted. Neurological examinations did not reveal any abnormality. She was looked after at another health care center three weeks prior to her admission as a case of alcoholic liver disease. She stopped drinking alcohol, but without improvement in her symptoms. Her investigations are as shown in Table 1.

Ultrasound of the abdomen showed hepatosplenomegaly and gross ascites. Ascitic fluid tap was done and sent for analysis, which showed WCC 100 cells/ $\mu \mathrm{L}$ (neutrophils $60 \%$ and lymphocytes $40 \%$ ), protein 1 gm/dl and albumin $0.5 \mathrm{gm} / \mathrm{dl}$. Upper gastrointestinal endoscopy showed small sized esophageal varices and mild portal hypertensive gastropathy. Hepatitis B surface antigen (HBsAg) and hepatitis C antibody were nonreactive. Direct Coombs test was negative. Patient was started on furosemide $20 \mathrm{mg}$ once daily, spironolactone $50 \mathrm{mg}$ once daily and thiamine $100 \mathrm{mg}$ once daily.

Slit lamp examination of her eyes showed the presence of Kayser-Fleischer (KF) rings. Twenty-four-hour urinary copper was 85.70 (normal <60) $\mu \mathrm{g}$ and serum ceruloplasmin level was 23 (normal 20-60) $\mathrm{mg} / \mathrm{dl}$. The diagnosis of subacute liver failure with Wilson's disease was made. We started oral zinc acetate (50 mg elemental zinc thrice daily) along with the above drugs and she was discharged in one week of admission. There was clinical and biochemical improvement as seen during one-month (January 2019) and 11 months (November 2019) follow-up visits (Table 1).

\section{Discussion}

This female patient who presented with features of chronic liver disease had a history of alcohol intake for almost 12 years. Nepal is a low-income country in South Asia, and a full chronic liver disease screening (including tests for Wilson's disease, autoimmune hepatitis, hemochromatosis) is usually not possible in the Nepali health setup. The limited screen includes alcohol history, history of any drug or toxin use and serologies for hepatitis B and C. ${ }^{2}$ However, the people mostly consume home-made alcohol in Nepal, and the exact quantification is usually not possible to estimate whether the amount of intake is significant enough to cause liver disease or not. ${ }^{3}$ We usually ascribe liver disease in any patient to the alcohol, no matter the amount of intake by the patient, especially if serologies are nonreactive and there is no drug or toxin exposure. In our patient with a history of alcohol use, we extended the tests beyond the conventional limited screen, which led to a diagnosis of Wilson's disease.

Basic liver function tests (LFT) including bilirubin, transaminases level and alkaline phosphatase (ALP) are available in most of the health centers in Nepal. In any patient with liver disease who presents with acute liver failure, the combined ratio of ALP/total bilirubin $(<4)$ and aspartate transaminase (AST)/alanine transaminase (ALT) ( $>2.2$ ) provides sensitivity and specificity of $100 \%$ for diagnosing Wilson's disease. ${ }^{4}$ In our patient, ALP/total bilirubin was 3.09 and AST/ALT was 3.4 during the admission (Table 2). Although she did not have acute liver failure during the presentation, we used this pattern of LFT (the 'Wilson's pattern') as a guide to suspect the possibility of Wilson's disease and ordered slit lamp examination of eyes for KF rings, serum ceruloplasmin level and 24-hour urinary copper tests.

The diagnosis was made using the Leipzig scoring system for Wilson's disease. ${ }^{5}$ Total points obtained were four (two for KF ring, one for Coombs negative hemolytic anemia, one for high 24-hour urinary copper), which established the 

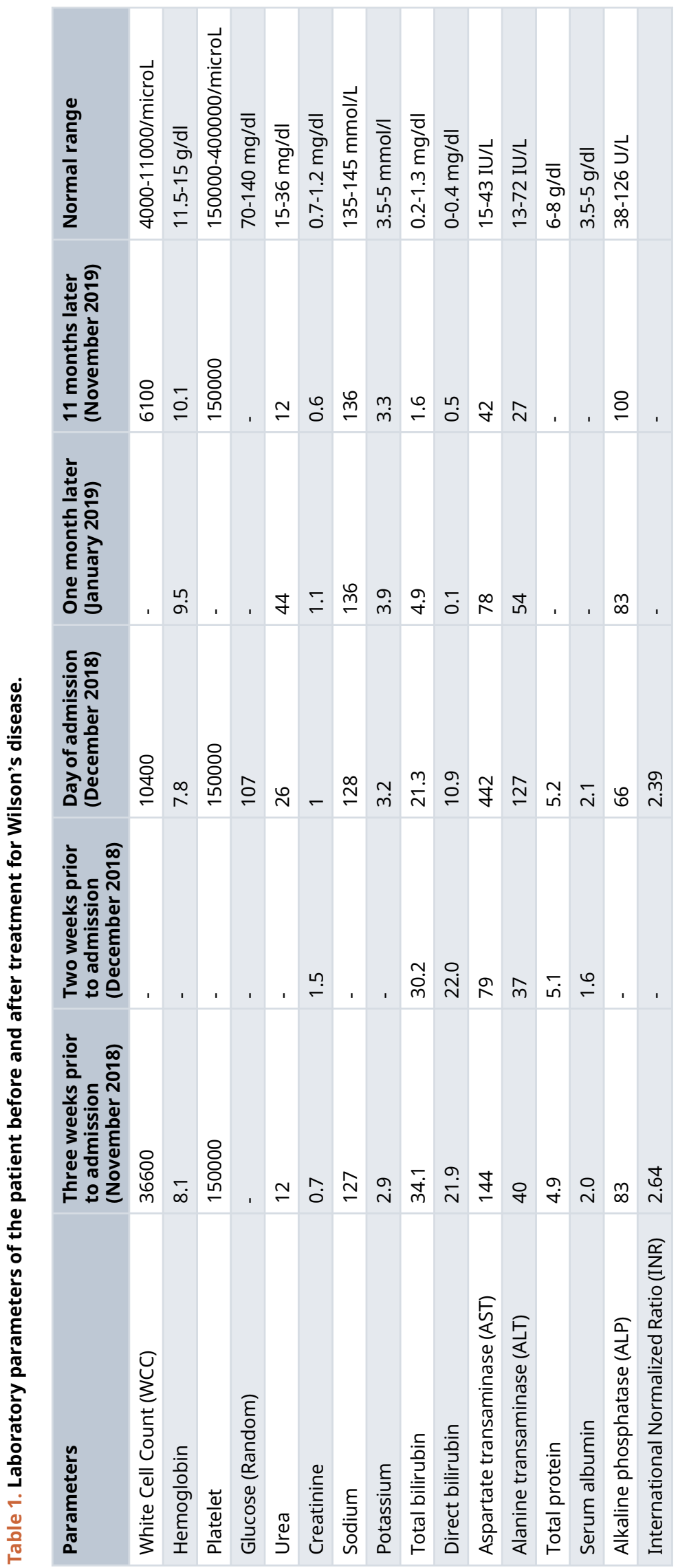
Table 2. Wilson's pattern of liver function tests of the patient before and after treatment. (alkaline phosphatase (ALP), aspartate transaminase (AST), alanine transaminase (ALT)).

\begin{tabular}{|l|l|l|}
\hline & ALP/total bilirubin & AST/ALT \\
\hline Three weeks prior to admission (November 2018) & 2.43 & 3.6 \\
\hline Day of admission (December 2018) & 3.09 & 3.4 \\
\hline One month later (January 2019) & 16.9 & 1.4 \\
\hline 11 months later (November 2019) & 62.5 & 1.5 \\
\hline
\end{tabular}

diagnosis of Wilson's disease. However, she had no neurologic symptoms and her serum ceruloplasmin level was normal. Liver copper and mutation analysis were not performed.

Treatment with zinc acetate was started in this case because of unavailability of chelating agents. On follow up in one month, she had no abdominal distension and jaundice. LFTs were improved, which continued to improve till 11 months follow up (Table 1). Even the 'Wilson's pattern' of LFTs was resolved with treatment (Table 2).

\section{Conclusion}

LFTs are simple and readily available tests even in remote parts of Nepal, done in all patients with liver disease. As screening for rare diseases is not always possible in low-income countries, this case demonstrates the usefulness of the 'Wilson's pattern' LFT as a guide for suspecting Wilson's disease in patients with liver disease. However, the sensitivity and specificity of this pattern is yet to be studied in patients with subacute liver disease.

\section{Data availability}

All data underlying the results are available as part of the article and no additional source data are required.

Consent

Written informed consent for publication of the clinical details and/or clinical images was obtained from the patient.

References

1. Patil $\mathrm{M}$, Sheth $\mathrm{KA}$, Krishnamurthy $\mathrm{AC}$, et al.: A review and current perspective on Wilson disease. J Clin Exp Hepatol. 2013 Dec 1; 3(4): 321-36.

PubMed Abstract | Publisher Full Text | Free Full Text

2. Gautam S, Sigdel KR, Adhikari S, et al.: Case Report: Pulmonary tuberculosis and raised transaminases without pre-existing liver disease-Do we need to modify the antitubercular therapy? Wellcome Open Res. 2020; 5.

PubMed Abstract | Publisher Full Text | Free Full Text

3. Pradhan B, Hadengue A, Chappuis F, et al.: Alcoholic liver disease

in Nepal: identifying homemade alcohol as a culprit. Clin Exp

Gastroenterol. 2015; 8: 183

PubMed Abstract | Publisher Full Text | Free Full Text

4. Korman JD, Volenberg I, Balko J, et al.: Screening for Wilson disease in acute liver failure: a comparison of currently available diagnostic tests. Hepatology. 2008 Oct; 48(4): 1167-74.

PubMed Abstract | Publisher Full Text | Free Full Text

5. European Association For The Study Of The Liver: EASL clinical practice guidelines: Wilson's disease. J Hepatol. 2012 Mar 1; 56(3): 671-85.

PubMed Abstract | Publisher Full Text 


\section{Open Peer Review}

\section{Current Peer Review Status:}

\section{Version 1}

Reviewer Report 09 December 2021

https://doi.org/10.5256/f1000research.58069.r100231

(C) 2021 Burkhead J. This is an open access peer review report distributed under the terms of the Creative Commons Attribution License, which permits unrestricted use, distribution, and reproduction in any medium, provided the original work is properly cited.

\section{Jason L. Burkhead \\ Department of Biological Sciences, University of Alaska Anchorage, Anchorage, AK, USA}

Wilson Disease is considered a rare disease, though recent studies indicate that specific populations may have significantly greater prevalence than the generally accepted 1:30,000 (e.g. estimated 1:3,000 for S. Korea). It is also accepted that Wilson Disease can be challenging to diagnose. The authors of this case report that after an initial diagnosis of alcoholic liver disease and symptoms that did not improve after cessation of alcohol consumption, further etiologies were considered. Notably, the authors applied the "Wilson Pattern" of liver function tests as an initial motivation to specifically assess Wilson Disease, including slit lamp examination and parameters that can be used in the Leipzig Score.

The overall message of this report is that the Wilson pattern of liver function tests is important in diagnosis, particularly in developing countries that may be resource-limited. This message is not particularly novel, but it is valuable to highlight. The Wilson pattern was developed based on patients with acute liver failure, however. It is not yet known whether the specificity and sensitivity of the test is $100 \%$ in subacute liver disease-as the authors note under the Conclusion section. This observation as well as the qualifier are useful to highlight and enhance the importance of the report.

It appears from the report that the choice to use $\mathrm{Zn}$ was made due to the lack of chelator availability. The report indicates " $50 \mathrm{mg}$ elemental zinc thrice daily." It is expected that a zinc salt was prescribed, where it would be important to report the specific salt used. The observation that the patient's liver function tests improved with zinc supplementation is promising and may be useful to others. Given the apparent ability to assess 24-hour urinary $\mathrm{Cu}$, it would be interesting to know if this value changed with treatment.

In summary, this is an important case report in that it promotes consideration of liver function tests in suspicion of Wilson Disease, which is particularly valuable in locations where specialized diagnostic resources are limited. The apparent successes in the case are also notable.

\section{Is the background of the case's history and progression described in sufficient detail?}


Yes

Are enough details provided of any physical examination and diagnostic tests, treatment given and outcomes?

Yes

Is sufficient discussion included of the importance of the findings and their relevance to future understanding of disease processes, diagnosis or treatment?

Partly

Is the case presented with sufficient detail to be useful for other practitioners?

Partly

Competing Interests: No competing interests were disclosed.

Reviewer Expertise: Expertise in basic biology of Wilson Disease and working knowledge of diagnostic procedures.

I confirm that I have read this submission and believe that I have an appropriate level of expertise to confirm that it is of an acceptable scientific standard.

Author Response 14 Jan 2022

Sudeep Adhikari, Pyuthan Hospital, Pyuthan, Nepal

Thank you for the review, and the constructive feedback.

Competing Interests: none

Reviewer Report 09 August 2021

https://doi.org/10.5256/f1000research.58069.r89924

(C) 2021 Iorio R. This is an open access peer review report distributed under the terms of the Creative Commons Attribution License, which permits unrestricted use, distribution, and reproduction in any medium, provided the original work is properly cited.

\section{Raffaele Iorio}

Department of Translational Medical Science, Section of Pediatrics, University of Naples Federico II, Naples, Italy

Since screening for rare diseases is not always possible in low-income countries, with this case report the authors emphasize the usefulness of the 'Wilson's pattern' LFT as a guide for suspecting Wilson's disease in patients with liver disease. Certainly the case report is of value if we contextualize it and if we take into account the error of easily attributing patients' liver disease to alcohol without conducting an appropriate differential diagnosis. However, the message of the 
studies itself is very limited and not original. As the authors themselves point out, sensitivity and the specificity of this model has yet to be validated in patients with subacute liver disease so the authors' observation, although simulating, cannot be considered as a sure proof of the diagnostic reliability of the test. Certainly the authors should be congratulated for the diagnostic suspicion.

Regarding the patient's definition of negative Coombs hemolytic anemia, which gave her a score of 1 according to the Leipzig score, I believe that for the definition of hemolysis it was necessary to have the result of the reticulocytes. In other words, to be defined haemolytic anemia required other parameters (reticulocytes, indirect bilirubin, haptoglobin, etc).

Given the presence of cirrhosis and ascites, a comment should be done on the choice of therapy with zinc instead of chelating.

Is the background of the case's history and progression described in sufficient detail? Partly

Are enough details provided of any physical examination and diagnostic tests, treatment given and outcomes?

Partly

Is sufficient discussion included of the importance of the findings and their relevance to future understanding of disease processes, diagnosis or treatment?

Partly

Is the case presented with sufficient detail to be useful for other practitioners?

Yes

Competing Interests: No competing interests were disclosed.

Reviewer Expertise: Liver disease, Wilson' disease, pediatric liver disease

I confirm that I have read this submission and believe that I have an appropriate level of expertise to confirm that it is of an acceptable scientific standard, however I have significant reservations, as outlined above.

Author Response 14 Jan 2022

Sudeep Adhikari, Pyuthan Hospital, Pyuthan, Nepal

Thank you for the constructive feedback.

Changes have been made in the revised version regarding the issues raised.

Regarding Coombs negative hemolytic anemia, details regarding indirect bilirubin and reticulocyte count have been added, however haptoglobin level was not tested.

Regarding choice of therapy with zinc acetate instead of d-penicillamine, the fact that the $d$ - 
penicillamine was not available for use has been acknowledged in the revised manuscript. Competing Interests: none

The benefits of publishing with F1000Research:

- Your article is published within days, with no editorial bias

- You can publish traditional articles, null/negative results, case reports, data notes and more

- The peer review process is transparent and collaborative

- Your article is indexed in PubMed after passing peer review

- Dedicated customer support at every stage

For pre-submission enquiries, contact research@f1000.com 